\title{
LiSC: Living in Shared Community
}

\author{
MARK MUECKENHEIM \\ Academy of Art University
}

The inextricable link between housing and labor has not been taken up as a central tenet since Modernism. Though the failure of Modernism in terms of public space has been discussed extensively across both architecture and planning circles, the fact that housing was a pivotal concern to Modernism has been lost and yet to be fully resurrected in architecture. At a time when growing inequities are quantitatively proven and qualitatively assessed repeatedly, focusing on competitions that promote a new museum or a new reclaimed waterfront without also addressing the nature of housing and labor is a lost opportunity.

While it is true that the chances of winning an open competition are low, and that participating in an open competitions requires a fair amount of free labor, there are certain competitions that are worthy of our attention precisely because they are a venue for promoting changes and disruptions to normalized ideas of space, typology, and equity. The project here, LiSC, is a housing proposal that utilizes the concept of a shared economy to address the chronic housing challenges facing cities worldwide by promoting a socially, economically, and environmentally sustainable community in Hong Kong, where the housing crisis is especially and increasingly acute. In this context, with this project we argue that the point in entering competitions is to challenge a given typology, particularly as it relates to larger questions of equity, which in this case is the typology of housing.

The increase in efficiency allows for the presence of amenities that are usually associated with more luxurious apartment complexes, such as roof gardens, spas, sport facilities and food access, among many others. Rather than accepting the underutilization of living units throughout the city of Hong Kong, only what is necessary at any given moment of use is rented, immediately generating affordability for lower and middle-income urban populations. In addition to the clear economic benefits, this increase in efficient use generates social and cultural amenities through an increase in the communal activities that take place in the public spaces throughout the project.

Taking seriously the framework of a shared economy that we find ourselves in today, the open competition that asks us to reconsider the typology of housing offers this project the opportunity to disrupt universal ideas on what constitutes urban living in a way that reverberates across the social, economic, and environmental impacts of housing.

\section{TSZ WEI LEUNG}

Academy of Art University

Before completing the project, it was entered into the Hong Kong Pixel Home Competition organized by an architecture competition organizer, which runs a high number of competitions that are open to students. Out of many submissions from all over the world, LiSC: Living in Shared Community won an Honorable Mention, one of 10 Prizes in total. 


\section{LiSC: \\ Siving in Community}

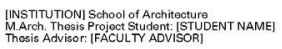

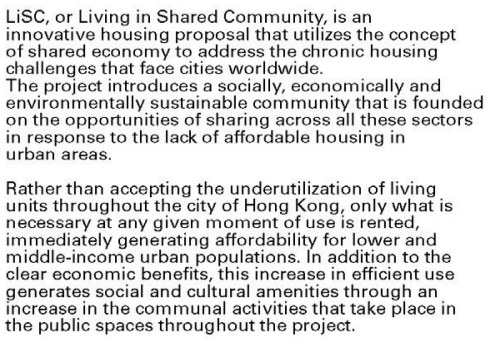

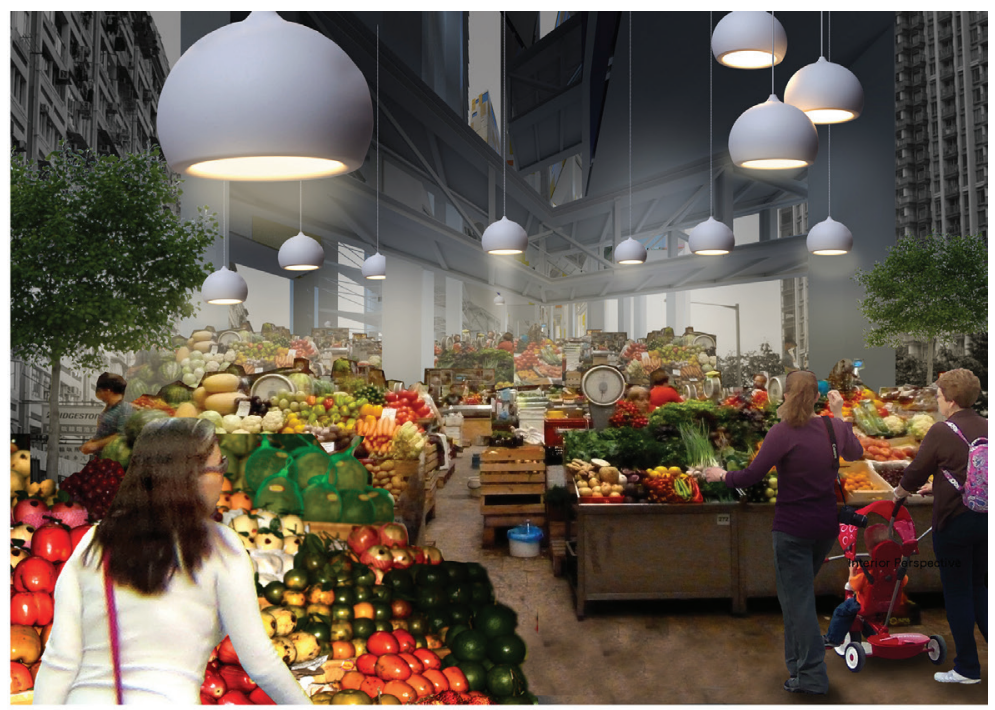
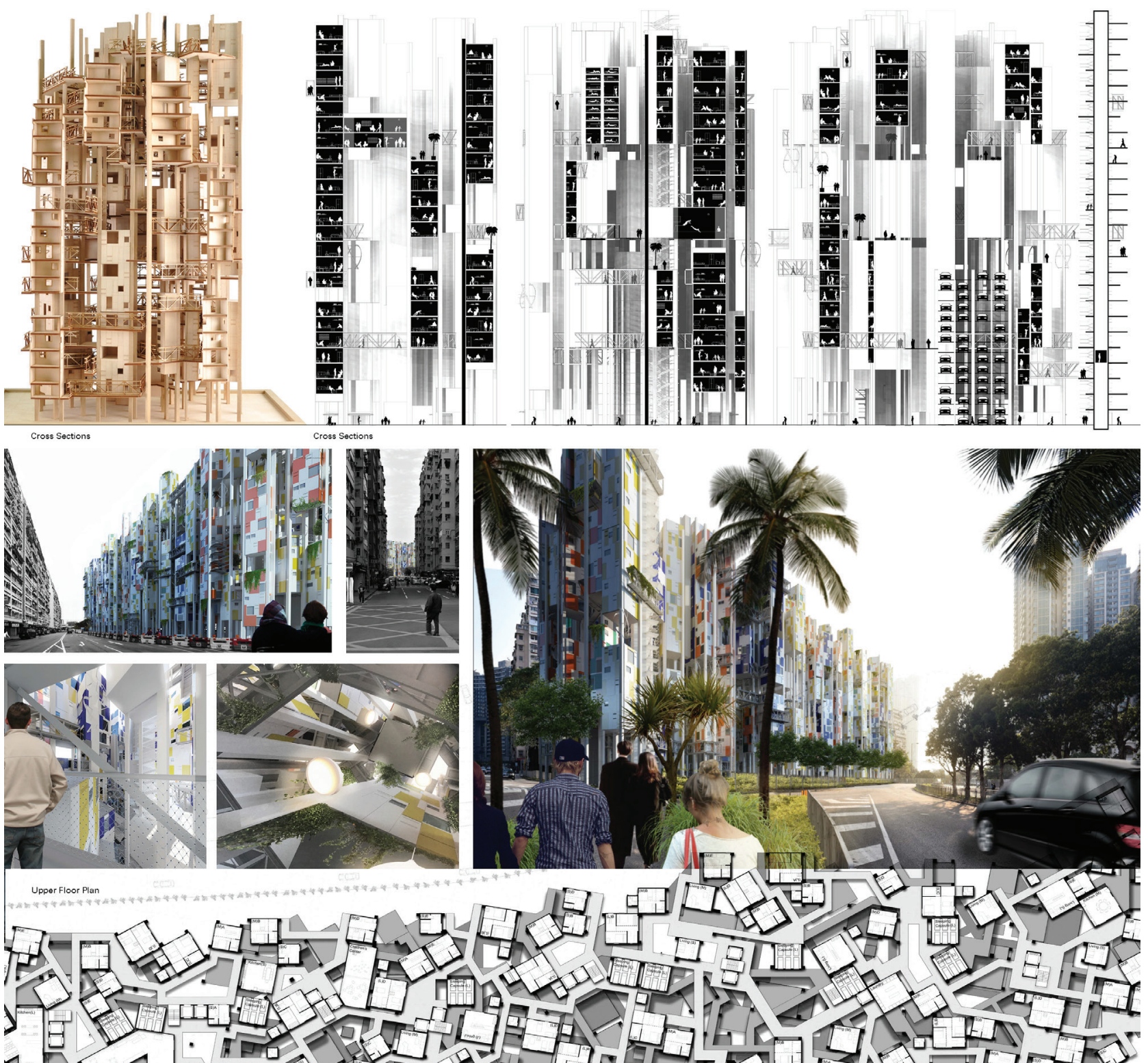